systems could favor the localization of tellurium either by means of interstitial or substitutional solid solution.

The nature of the active sites in oxidative dehydrogenation of 1-butene to butadiene has also been discussed in terms of possible formation of $\mathrm{Te}=\mathrm{O}$ groups or modification of $\mathrm{Mo}=0$ groups previously present or even formation of $\mathrm{Te}=\mathrm{O} \mathrm{Mo}=\mathrm{O}$ gem groups.

\section{Acknowledgments}

We thank Professor I. Pasquon for encouragement and useful discussion and Italian Consiglio Nazionale delle Ricerche (Rome) for financial support.

\section{Literature Cited}

Abrahams, S. C., Reddy, J. M., J. Chem. Phys., 43 (7), 2533 (1965)

Andrushkevich, T. V., Boreskov, G. K., Kuznetsova, L. M. Plyasova, L. M., Tyurin,

Yu. N., Shehekochikhin, Yu. M., Kinet. Katal., 15, 424 (1974).

Azarbayejani, G. H., J. Appl. Phys., 43 (9), 3880 (1972).

Barker, A. S., Jr., Phys. Rev., 135, A744 (1964).

Bart, J. C. J., Petrini, G., Giordano, N., Z. Anorg. Allg. Chem., 412, 258 (1975).

413, 180 (1975)

Bayer, G. Fortschr. Miner., 46, (1), 41 (1969)

Blasse, G., J. Electrochem. Soc., 115, 738 (1968).
Cairati, L., Trifirò, F., Villa, P. L., Italian Patent 25545 A 74 (July 25, 1974). Chen, M. C., Artman, J. O., Sengupta, D., Henning, J. C. M., Phys. Rev. B, 4, 1387 $(\uparrow 971)$

Courtine, P., Cord. P. P., Pannetier, G., Daumas, J. C., Montarnal, R., Bull. Soc. Chim. Fr. 4816 (1968)

Grasselli, R. K., Suresh, D. D., J. Catal., 25, 273 (1972).

Hucknal, J., "Selective Oxidation of Hydrocarbons", Academic Press, London, 1974

Isaev, O. V., Margolis, L. Ya., Kushnerev, M. Ya., Russ. J. Phys. Chem., 47 (8), 1198 (1973).

Krabetz, R., Chem. Ing. Techn., 46 (24), 1029 (1974)

Margolis, L. Ya., Firsov, A. A., in "Kinetics Problems and Catalysis", Vol. 16, (Surface Compounds in Heterogeneous Catalysis) p 98, lzd. Nauka, Moscow, 1975.

Plyasova, L. M., Klevtsova, R. F., Borisov, S. V., Kefeli, L. M., Sov. Phys. Dokl. $11(3), 189(1966)$

Sala, F., Trifirò, F., J. Catal., 41, 1 (1976).

Smith, G. W., Ibers, J. A., Acta Cryst., 19, 269 (1965).

Tajbl, D. G., Simons, J. B., Carberry, J. J., Ind. Eng. Chem., Fundam., 5, 171 (1966).

Trifirò, F., Banfi, C., Caputo, G., Forzatti, P., Pasquon, I., J. Catal., 30, 393 (1973).

Trifirò, F., Caputo, G., Villa, P. L., J. Less-Common Metals, 36, 305 (1974).

Trifirò, $\mathrm{F} /=$ Caputo, G., Forzatti, P., Ind. Eng. Chem., Prod. Res. Dev., 14, 22 (1975).

Voge, H: H., Adams, C. R., Adv. Catal., 17, 151 (1967).

\title{
Catalytic Oxidation of Hydrogen Sulfide. Influence of Pore Structure and Chemical Composition of Various Porous Substances
}

\author{
Matt Steijns ${ }^{1}$ and Pieter Mars* \\ Twente University of Technology, Department of Chemical Engineering, Enschede, The Netherlands
}

\begin{abstract}
The catalytic oxidation of $\mathrm{H}_{2} \mathrm{~S}$ with $\mathrm{O}_{2}$ at $200^{\circ} \mathrm{C}$ on various porous materials was investigated. The influence of the pore structure and the chemical composition of the materials on the activity and the selectivity toward the product (sulfur) was studied. It was found that in materials with an average pore diameter between 5 and $10 \AA$ the sulfur adsorption is strong. The catalytic activity per square meter of total surface area is approximately proportional to the amount of adsorbed sulfur. In this case the selectivity toward sulfur is high. In materials with larger pores sulfur adsorption is enhanced by the presence of Lewis acid sites and by a hydrophobic surface. For these materials the presence of water in the feed has an activity lowering effect. If iron oxide is present, at 200 ${ }^{\circ} \mathrm{C}, \mathrm{SO}_{2}$ is the main product. This is the case when other group 6-8 metal ions are present. For practical use in an $\mathrm{H}_{2} \mathrm{~S}$ removal process the industrial active charcoals, zeolite $\mathrm{NaX}, \mathrm{TiO}_{2}$, and $\mathrm{ZrO}_{2}$ are most suitable.
\end{abstract}

\section{Introduction}

Hydrogen sulfide in concentrations below $10 \mathrm{vol} \%$ may be removed from a gas stream by selective oxidation to sulfur. Oxygen is used as an oxidant at temperatures below $250^{\circ} \mathrm{C}$. Practically every porous solid shows catalytic activity for the oxidation of $\mathrm{H}_{2} \mathrm{~S}$. There exist, however, large differences in activity and selectivity which are associated with the chemical composition and the pore structure: The materials which were investigated can be divided in some groups with a cognate chemical composition: (1) carbonaceous solids, (2) zeolites, (3) silica, (4) alumina, and (5) other oxides $\left(\mathrm{MgO}, \mathrm{TiO}_{2}, \mathrm{ZrO}_{2}\right.$, $\mathrm{Fe}_{2} \mathrm{O}_{3}$ ). Within one group of materials there may be large variations in the pore structure. Furthermore it is possible to modify the surface composition of solids such as alumina or silica either by a heat treatment or by admixing water to the

${ }^{1}$ Laboratorium voor 'Tetrochemische Techniek, Rÿksuniversiteit, Gent, Belgium. reactor feed. In this way the concentration of $\mathrm{OH}$ groups at the surface may be varied.

In the first paper of a series on the oxidation of $\mathrm{H}_{2} \mathrm{~S}$ (Steijns and Mars, 1974) we demonstrated that the product sulfur adsorbed in the pores has a catalytic activity. The porous substance is actually a carrier for the catalyst sulfur. This carrier is not necessarily inactive for the oxidation of $\mathrm{H}_{2} \mathrm{~S}$. For example, traces of iron oxide ( $1000 \mathrm{ppm})$ may drastically increase the activity of the carrier (Steijns and Mars, 1974). Characteristic for the autocatalytic effect of adsorbed sulfur are the following.

(1) The appearance of a maximum activity is a function of the amount of sorbed sulfur by a material. As we demonstrated in a previous paper (Steijns et al., 1976a), this maximum corresponds to a maximum in the specific sulfur surface area. The activity maximum is often not observed because of a high intrinsic catalytic activity of the carrier.

(2) The stationary activity level is attained when the pore volume is for the greater part filled with sulfur. In this sta- 
Table I. Materials Used in This Investigation

\begin{tabular}{|c|c|c|}
\hline No. & Material & Supplier/preparation \\
\hline \multicolumn{3}{|c|}{ I. Carbonaceous Materials } \\
\hline 1. & $\begin{array}{l}\text { Carbon black } \\
\text { Sterling MT-FF }\end{array}$ & $\begin{array}{l}\text { Ketjen-AKZO } \\
\text { (Netherlands) }\end{array}$ \\
\hline 2. & $\begin{array}{l}\text { Carbon black } \\
\text { NA-KF21T1 }\end{array}$ & $\begin{array}{l}\text { Ketjen-AKZO } \\
\text { (Netherlands) }\end{array}$ \\
\hline 3. & Pyrolysed sugar char & (Our lab) \\
\hline 4. & Activated sugar & $\begin{array}{l}\text { Norit Research lab } \\
\text { (Amersfoort Neth.) }\end{array}$ \\
\hline 5. & $\begin{array}{l}\text { Gas chromato- } \\
\text { graphic grade }\end{array}$ & $\begin{array}{l}\text { Coast Engineering Lab } \\
\text { California, USA }\end{array}$ \\
\hline 6. & RBW1 & NORIT (Neth.) \\
\hline 7. & ROW 0.8 Supra & NORIT (Neth.) \\
\hline 8. & AEROSORB F30/430 & Degussa (GFR) \\
\hline 9. & KATEPON IV & Degussa (GFR) \\
\hline \multicolumn{3}{|c|}{ II. Zeolites } \\
\hline 10. & $\mathrm{NaX}, 20$ wt $\%$ binder & Union Carbide, U.S.A. \\
\hline 11. & $\mathrm{NaX}$ without binder & Union Carbide, U.S.A. \\
\hline 12. & CaA 20 wt \% binder & Union Carbide, U.S.A. \\
\hline 13. & $\mathrm{NaA} 20$ wt \% binder & Union Carbide, U.S.A. \\
\hline 14. & Chabasite AW500 & Union Carbide, U.S.A. \\
\hline 15. & Klinoptilolite & Hector, Calif. USA \\
\hline \multicolumn{3}{|c|}{ III. Silica } \\
\hline 16. & $\mathrm{SiO}_{2}$-Aerosil 380 & Degussa (GFR) \\
\hline 17. & $\mathrm{SiO}_{2}$-FK 700 & Degussa (GFR) \\
\hline 18. & $\mathrm{SiO}_{2}$-microporous & Gembo-AKZO (Neth.) \\
\hline 19. & $\mathrm{SiO}_{2}-\mathrm{FD}$ & our lab (Okkerse, 1961) \\
\hline \multicolumn{3}{|c|}{ IV. Alumina } \\
\hline 20. & $(\gamma+\delta)-\mathrm{Al}_{2} \mathrm{O}_{3}$ & Degussa (GFR) \\
\hline 21. & $\gamma-\mathrm{Al}_{2} \mathrm{O}_{3}$ & Ketjen-AKZO (Neth.) \\
\hline \multicolumn{3}{|c|}{ V. Other materials } \\
\hline 23. & Silica-alumina LA-3P & $\begin{array}{l}\text { erials } \\
\text { Ketjen-AKZO (Neth.) }\end{array}$ \\
\hline 24. & $\mathrm{MgO}$ & $\begin{array}{l}\text { our lab (Krause and } \\
\quad \text { Plura, 1965) }\end{array}$ \\
\hline 25. & $\mathrm{TiO}_{2} \mathrm{P} 25$ & Degussa (GFR) \\
\hline 26. & $\mathrm{ZrO}_{2}$ & Our lab (Rijnten, 1971) \\
\hline 27. & $\mathrm{Fe}_{2} \mathrm{O}_{3}$ & $\begin{array}{l}\text { Our lab (Fricke and } \\
\text { Ackermann, 1934) }\end{array}$ \\
\hline
\end{tabular}

tionary state all the produced sulfur should leave the reactor as sulfur vapor. This implies that there exists a minimum working temperature, which depends on the partial pressure of $\mathrm{H}_{2} \mathrm{~S}$ and the conversion.

(3) A high selectivity toward sulfur formation at temperatures between 20 and $250^{\circ} \mathrm{C}$ is realized with excess oxygen present despite the fact that in this temperature range $\mathrm{SO}_{2}$ and $\mathrm{SO}_{3}$ are thermodynamically the most favored products if oxygen is in excess.

The adsorption of the catalyst sulfur by a porous material will be determined by its pore structure and its chemical composition. It may be expected that more adsorption takes place as the average pore size is smaller and as the surface has a greater affinity toward sulfur.

The catalytic activity does not correlate with the amount of adsorbed sulfur but with the extent of the specific sulfur surface area. Furthermore, the concentration of active sites, i.e., surface radicals, depends on the composition and the pore structure of the materials. For sulfur adsorbed in zeolite $\mathrm{NaX}$ $(=13 \mathrm{X})$ at $150^{\circ} \mathrm{C}$ we found a radical concentration which was a factor of 1000 higher than for nonadsorbed sulfur (Steijns et al., 1976b).

In this study a large variety of materials was screened as to catalytic activity and selectivity. Besides these substances, some others are mentioned in literature which we did not test. In the first place, the oxides and sulfides of $\mathrm{Co}, \mathrm{Mo}, \mathrm{Ni}, \mathrm{W}, \mathrm{V}$, $\mathrm{Cr}$, and Mn (Cook and Ross, 1973; Ross and Jeanes, 1974; Gmelin, 1953), are active but not selective. Secondly, some of the materials have a complicated chemical composition be- cause promotors are added (Gmelin, 1953; Storp, 1970); this makes them less suitable for this investigation.

For a comparison we will select those materials which are suitable for a continuous removal of hydrogen sulfide from gas streams by catalytic oxidation with oxygen.

\section{Experimental Methods}

Materials. In Table I a survey of the materials which were investigated is given. The sieve fraction $0.3-0.6 \mathrm{~mm}$ was used in the experiments.

Activity Measurements. The activity of a catalyst was measured in the apparatus which is described in a previous paper (Steijns and Mars, 1974). The conversion of $\mathrm{H}_{2} \mathrm{~S}$ was determined gas chromatographically and the oxygen conversion was determined with an oxygen meter (Teledyne, Model 311). Before this, the solids were dried in a stream of $500 \mathrm{~cm}^{3} \mathrm{~min}^{-1}$ dry nitrogen at $200^{\circ} \mathrm{C}$ during $1 \mathrm{~h}$. In practically all the experiments we used the following reaction conditions: temperature: $200^{\circ} \mathrm{C}$; feed: $500 \mathrm{~cm}^{3} \mathrm{~min}^{-1}$ nitrogen containing $0.5 \mathrm{vol} \% \mathrm{H}_{2} \mathrm{~S}$ and $0.4 \mathrm{vol} \% \mathrm{O}_{2}$; amount of material: $0.8-1 \mathrm{~g} . \mathrm{A}$ fixed bed of material (diameter $0.8 \mathrm{~cm}$ ) was used which was heated by a fluid-bed heating furnace.

If all the $\mathrm{H}_{2} \mathrm{~S}$ were converted into sulfur $\left(\mathrm{S}_{8}\right.$ in the vapor phase) a maximum relative sulfur pressure of 0.23 at $200^{\circ} \mathrm{C}$ would be obtained. This implies that at a constant activity level all the produced sulfur is in the vapor phase when leaving the reactor. As a measure for the activity we used mostly \% $\mathrm{H}_{2} \mathrm{~S}$ conversion per unit of surface area at the constant activity level. The use of this apparently rough measure is considered in the first part of the discussion. In some of the figures the $\%$ oxygen conversion is used as a measure for the activity because the continuous and automatic registration of the oxygen conversion is suitable to study the course of the activity as a function of reaction time.

The selectivity toward sulfur was calculated from a comparison of the oxygen and hydrogen sulfide consumption rates, assuming that the only by-product is sulfur dioxide. If the conversion was below $5 \%$, the selectivity was not calculated because the experimental error is too high.

The weight increase of a solid was determined when the constant activity level was reached. This weight increase is for the greater part due to the deposition of elemental sulfur.

Sulfur Adsorption. The sulfur uptake during reaction was compared with the amount of sulfur adsorbed by a porous material from a nitrogen-sulfur gas mixture under comparable conditions. A nitrogen stream was saturated with sulfur at temperatures ranging from 140 to $160^{\circ} \mathrm{C}$. By admixing nitrogen to this stream, the relative pressure of sulfur at the adsorbent outer surface could be varied. In this study the sulfur relative pressure was maintained at a value of 0.1 at an adsorption temperature of $200^{\circ} \mathrm{C}$. The quantity of adsorbed sulfur was determined gravimetrically. The apparatus and the procedure are described in detail in a preceding paper (Steijns and Mars, 1976).

Investigation of Surface Area and Pore Structure. The surface area was calculated from a part of the argon adsorption isotherm, determined at $-196{ }^{\circ} \mathrm{C}$, using the BET method. For the microporous materials, such as active carbon and zeolites, the calculated BET surface area is not a good measure for the real surface area. In this case an estimation of the micropore volume may be obtained from the argon adsorption isotherm.

The total open pore volume of the pores with a diameter 4 $\AA<d_{p}<150.000 \AA$ was derived from the apparent material volumes in methanol and mercury at $20^{\circ} \mathrm{C}$. The pore volume radius distribution in the range $75<d_{\mathrm{p}}<150.000 \AA$ was determined with a mercury porosimeter (Carlo Erba Type 70; maximum pressure $2 \times 10^{8} \mathrm{Nm}^{-2}$ ). In the calculations we used a value of $140^{\circ}$ for the contact angle between mercury and all 


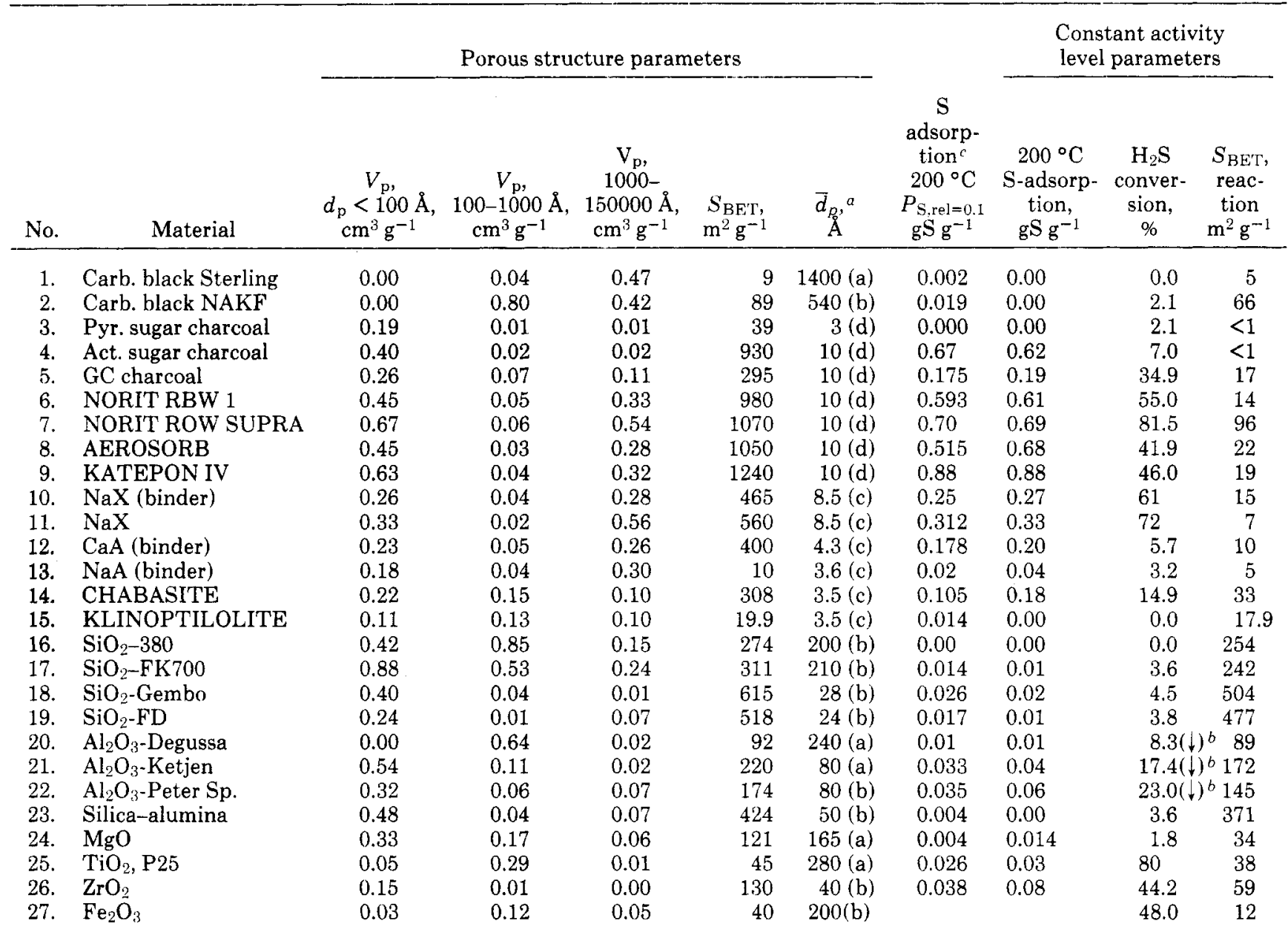

${ }^{a}$ Indicated method, i.e. (a), (b), (c) or (d) as described in Experimental Methods. ${ }^{b}(\downarrow)$ no constant activity level, decreasing activity. The selectivity was generally between 80 and $100 \%$, an exception is $\mathrm{Fe}_{2} \mathrm{O}_{3}$ with a selectivity of $23 \%$. " This column pertains to sulfur adsorption by a porous material from a nitrogen-sulfur gas mixture.

the materials. An estimation of the average pore diameter $\left(\bar{d}_{\mathrm{p}}\right)$ could be obtained: (a) from mercury porosimetry if the greater part of the pore volume is in the pores with $d_{\mathrm{p}}>75 \AA$; (b) from the BET surface area $\left(S_{\mathrm{BET}}\right)$ and the total pore volume $\left(V_{\mathrm{p}}\right)$ under the assumption of cylindrical pores: $\bar{d}_{p}=4 V_{\mathrm{p}} / \mathrm{S}_{\mathrm{BET}}$; this relation was not used for microporous materials such as zeolites and active carbons because they have a bimodal pore-size distribution; (c) from crystallographic data in literature (Breck, 1974) for zeolites; (d) from various literature data (Dubinin, 1975; Bond, 1967) for active carbons. For (c) and (d) the average pore diameter of only the microporous system is considered, which is smaller than the overall average pore diameter.

\section{Results}

The Behavior of Various Porous Materials. To give an impression of the different behavior of the various materials, the time dependency of the oxygen conversion, which is recorded continuously and automatically, is given for some of the materials in Figure 1. In the case of activated sugar charcoal and $\mathrm{ZrO}_{2}$ the conversion attains a maximum as a function of reaction time, which points to the catalytic activity of the produced sulfur. It is noteworthy that the initial activity of the other materials is high and decreases as a function of time in the reactor; ultimately a constant activity level may be reached. In Table II data on the pore structure, sulfur adsorption, and stationary activity and surface area are given for 27 materials.

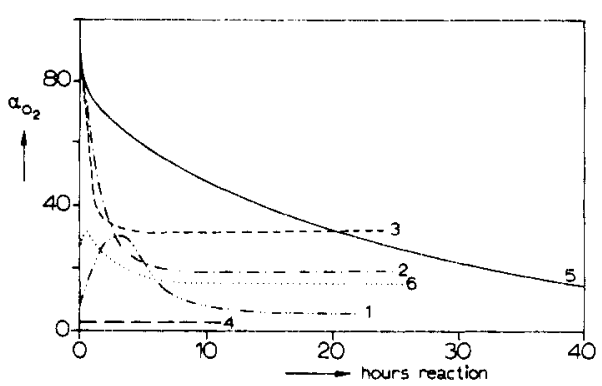

Figure 1. Activity, expressed as \% oxygen conversion as a function of time for various materials at $185^{\circ} \mathrm{C}: 1$, active sugar carbon (no. 4); 2, Katepon active carbon (no. 9); 3, zeolite $\mathrm{NaX}$ (no. 11); 4, $\mathrm{SiO}_{2}$-FD (no. 19);5, $\mathrm{Al}_{2} \mathrm{O}_{3}$-P. Spence (no. 22);6, $\mathrm{ZrO}_{2}$ (no. 26).

The most salient trends in the data presented in Table II are the following. (1) The weight increase of a material during reaction equals the weight increase of sulfur deposition on a material in separate sulfur adsorption experiments. This implies that during reaction elemental sulfur is the most predominant adsorbed species. The same conclusions may be drawn from the experimental observation that at least $90 \%$ of the adsorbed sulfur can be removed by benzene extraction. (2) Microporous materials with $5 \AA<\bar{d}_{\mathrm{p}}<10 \AA$, i.e., numbers 5-11 adsorb appreciable amounts of product sulfur. They combine a high activity with a high selectivity notwithstanding the low surface area in the stationary state. (3) Microporous 
Table III. The Influence of Admixing Water to the Feed on the Catalytic Activity of Various Materials. Conditions: Temperature: $200{ }^{\circ} \mathrm{C} ; 250 \mathrm{~cm}^{3} \mathrm{~min}^{-1} \mathrm{~N}_{2}$ Containing 0.5 Vol. $\% \mathrm{H}_{2} \mathrm{~S}$ and $4 \mathrm{Vol} . \% \mathrm{O}_{2}$

\begin{tabular}{|c|c|c|c|c|c|c|}
\hline Material & $\begin{array}{l}\text { Vol. } \% \\
\mathrm{H}_{2} \mathrm{O}\end{array}$ & $d_{\mathrm{p}}, \AA$ & $\begin{array}{l}\text { Amounit of } \\
\text { material, } \\
\text { g }\end{array}$ & $\begin{array}{c}\text { reaction } \\
\text { time, } h\end{array}$ & $\begin{array}{c}\mathrm{H}_{2} \mathrm{~S} \\
\text { \% conversion }\end{array}$ & $\begin{array}{c}\text { Selectivity } \\
\%\end{array}$ \\
\hline \multirow[t]{2}{*}{$\mathrm{SiO}_{2}-380$ Degussa } & 0 & 200 & 4.811 & 19 & 0.6 & - \\
\hline & 1.4 & 200 & 4.811 & 21 & 0.0 & - \\
\hline \multirow[t]{2}{*}{$\mathrm{SiO}_{2}-\mathrm{FD} 1$} & 0 & 24 & 4.677 & 19 & 17.9 & 80 \\
\hline & 1.1 & 24 & 4.677 & 21 & 9.5 & 60 \\
\hline \multirow[t]{2}{*}{$\mathrm{Al}_{2} \mathrm{O}_{3}$-Degussa } & 0 & 240 & 0.863 & 40 & 15.4 & 98 \\
\hline & 1.4 & 240 & 0.863 & 42 & 5.3 & 83 \\
\hline \multirow[t]{2}{*}{$\mathrm{Al}_{2} \mathrm{O}_{3}$-Peter Spence } & 0 & 80 & 0.866 & 64 & 29.2 & 93 \\
\hline & 1.1 & 80 & 0.866 & 66 & 18.1 & 90 \\
\hline \multirow[t]{2}{*}{ NaX zeolite } & 0 & 8.5 & 0.779 & 24 & 84 & 91 \\
\hline & 1.1 & 8.5 & 0.779 & 26 & 72 & 89 \\
\hline \multirow[t]{2}{*}{ NORIT ROW Supra } & 0 & 10 & 0.875 & 19 & 92 & 75 \\
\hline & 1.1 & 10 & 0.875 & 21 & 84 & 67 \\
\hline \multirow{2}{*}{$\mathrm{ZrO}_{2}$} & 0 & 40 & 0.985 & 23 & 61 & 95 \\
\hline & 1.1 & 40 & 0.985 & 25 & 37 & 96 \\
\hline
\end{tabular}

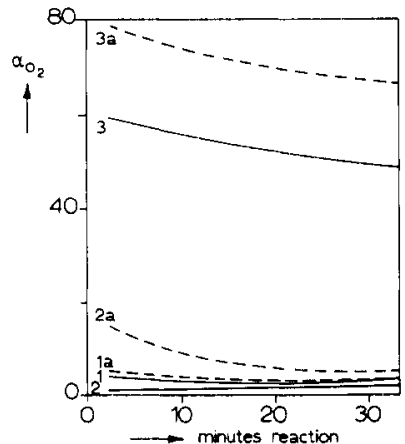

Figure 2. Influence of a heat pretreatment in nitrogen at $500^{\circ} \mathrm{C}$ on the $\%$ oxygen conversion at $185^{\circ} \mathrm{C}: 1$, carbon black NA-KF (no. 2); 2, $\mathrm{SiO}_{2}$-FD (no. 19); $3, \mathrm{Al}_{2} \mathrm{O}_{3}$-Degussa (no. 20); - . - -, heated at 600 ${ }^{\circ} \mathrm{C}$ (index a); —., not heated.

materials with pores smaller than $5 \AA$ in diameter, i.e., numbers $3,12,13,14$, are less active for the oxidation of $\mathrm{H}_{2} \mathrm{~S}$. (4) Within one group of materials an increase of the average pore size yields a less active catalyst (see $1-2$ and $5-9,16$, and 19, 20, and 22). (5) Some metal oxides show another behavior: (a) iron oxide (27): high activity; low selectivity; micropores absent; (b) titanium oxide (25); high activity and selectivity; micropores absent; (c) aluminum oxide (20-22): high activity and selectivity; no constant activity level even after $60 \mathrm{~h}$ reaction; (d) zirconium oxide (26): high activity and selectivity; micropores absent. The activity reaches a maximum when some product sulfur has already deposited in the pores (see Figure 1).

The Influence of Admixing Water Vapor to the Feed on the Activity. In Table III the experiments on the influence of water vapor on the conversion and selectivity are summarized. The concentration of water in the feed is higher by at least a factor 2 than the water concentration which would exist in the reactor outlet when all the $\mathrm{H}_{2} \mathrm{~S}$ would be converted. Table III shows that: (a) admixing of water leads to a decrease of activity, especially in the case of wide-pore alumina and silica; (b) the decrease of the activity is mostly accompanied by a decrease of the selectivity

The Influence of a High-Temperature Heat Pretreatment of a Material on the Initial Activity. In Figure 2 , experiments on the effect of a high-temperature treatment are summarized. In all cases an increase of the initial oxidation rate is observed.

\section{Discussion}

We reported recently on the kinetics of the autocatalytic oxidation of $\mathrm{H}_{2} \mathrm{~S}$ (Steijns et al., 1976c). The reaction rate $\left(r_{\mathrm{ox}}\right)$ as a function of the partial pressures of $\mathrm{O}_{2}\left(P_{\mathrm{O}_{2}}\right)$ and $\mathrm{H}_{2} \mathrm{~S}$ $\left(P_{\mathrm{H} . \mathrm{S}}\right)$ could be described with the kinetics of an oxidationreduction mechanism:

$$
r_{\mathrm{ox}}{ }^{-1}=\frac{1}{k_{\mathrm{ox}} \cdot P_{\mathrm{O}_{2}}}+\frac{1}{k_{\mathrm{red}} \cdot P_{\mathrm{H}_{2} \mathrm{~S}} \mathrm{~S}^{0.5}}
$$

Although this rate equation applies to the present results we will not use the reaction rate constants $k_{\mathrm{ox}}$ and $k_{\text {red }}$ as a measure for the catalytic activity. In the Experimental Methods section we defined the activity as \% conversion per unit of surface area at the constant activity level. The use of this rather rough measure for the activity is justified in the first place by the fact that the determination of $k_{\mathrm{ox}}$ and $k_{\text {red }}$ requires a more elaborate study because the ratio $k_{\text {ox }} / k_{\text {red }}$ depends on the type of materials (Steijns et al., 1973c). Another argument is that the reactor is not working isothermally and differentially. $\left(\Delta T_{\text {adiab }}=30^{\circ} \mathrm{C}\right.$ at $90 \%$ conversion $)$. The concentration gradient leads to an underestimation of the activity when the conversion per unit surface area is used as a measure. It is noteworthy that the temperature gradient, caused by the exothermic heat of reaction, has an opposite effect. Our calculation showed that in our experiments these two effects almost compensate each other if the reactor is adiabatic. In the latter case the conversion per unit of surface area is a rather good measure for the activity even at high conversion levels.

I. Influence of the Pore Size. In Figure 3 the relation between the activity and the average pore size is given. A similar figure could be obtained if the concentration of sorbed sulfur is plotted as a function of the average pore size. This implies that the activity is approximately proportional to the concentration of sorbed sulfur on the various materials, which is indicated in Figure 4. Obviously, the fraction of total surface area which is actually sulfur surface area increases with the amount of sorbed sulfur. The classification of materials in various groups, as given in the Introduction, will also be used to discuss the results (Table II and Figures 3 and 4).

(1) Industrial active charcoals are the most active catalysts among the group of carbonaceous materials. The activity of the wide-pore carbon blacks is rather low, especially if the activity per square meter of surface area is considered. This fact suggests that micropores are essential for an active carbonaceous material. There exists, however, an optimum pore diameter: pyrolyzed sugar charcoal has pores which are in- 


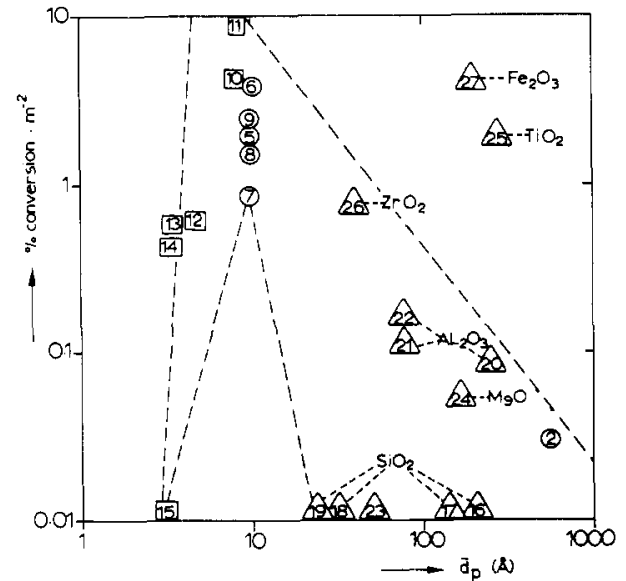

Figure 3. Influence of the average pore diameter on the activity (\% conversion $/ \mathrm{m}^{2}$ ) at the constant activity level. See Tables I and II for the numbers: $\bigcirc$, carbonaceous materials (no. 1-9); $\square$, zeolites (no. 10-15); $\Delta$, other materials (no. 16-27).

accessible to sulfur at $200^{\circ} \mathrm{C}$ but adsorption of methanol ( $d$ $=4 \AA$ ) at room temperature is possible. Steam activation of the latter material yields an active charcoal with larger pores. For this material the course of the activity as a function of time (Figure 1) is characteristic for the autocatalytic effect of sulfur. Another remarkable aspect of this active sugar charcoal is the rather low activity in the stationary state, which is connected with a low surface area $\left(<1 \mathrm{~m}^{2} \mathrm{~g}^{-1}\right)$. This is in contrast with the high activity and the surface area $\left(10-100 \mathrm{~m}^{2} \mathrm{~g}^{-1}\right)$ of the industrial active charcoals on the constant activity level. This difference must be due to the pore structure. From mercury porosimetry we learned that in the activated sugar charcoal the greater part of the pore volume is in the micropore range. The industrial active charcoals, however, have an appreciable meso- and macropore volume. These meso- and macropores are not filled with sulfur and in this way the exposed surface of the sulfur is relatively large for the industrial active charcoals when the micropore volume is filled with sulfur.

Swinarski and Siedlewski (1961) also studied the influence of the pore structure of active carbon on the activity for $\mathrm{H}_{2} \mathrm{~S}$ oxidation. They found that the catalytic activity is proportional to the surface area of the pores with a diameter between 35 and $80 \AA$. Adsorption of oil vapor in these pores leads to a decrease of the surface area and the catalytic activity. They did not offer an explanation for the phenomenon. In combination with our observations regarding the activity of carbonaceous materials we may draw the general conclusion that the optimum pore structure is related to the presence of many short micropores, with their outlets in an interconnecting net of meso- and macropores.

(2) For the zeolites we observed a decrease of the activity in the sequence $\mathrm{NaX}(d=8.5 \AA), \mathrm{CaA}(d=4.3 \AA)$ and $\mathrm{NaA}(d$ $=3.6 \AA$ ). These results corroborate the findings disclosed in an American patent (Johnson and Kerr, 1961).

The behavior of the NaA zeolite is identical with pyrolyzed sugar charcoal: a very low activity and no sulfur adsorption. Separate experiments with binderless $\mathrm{NaA}$ zeolite showed that this low activity originates from the external surface of the zeolite crystals. The same surface area is available for catalysis in case of $\mathrm{NaX}$ when the micropore volume is filled with sulfur. Part of the external surface area of the zeolite crystals is now sulfur surface, which explains the activity difference between $\mathrm{NaA}$ and $\mathrm{NaX}$. The zeolites $\mathrm{CaA}$ and chabasite show an intermediate behavior. Adsorption of sulfur takes place but the activity on the stationary state is rather low. A similar observation was made in the case of activated sugar charcoal.

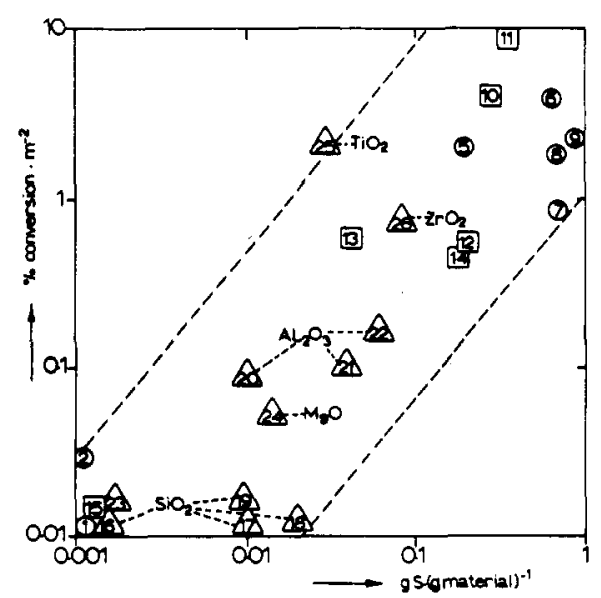

Figure 4. Relation between the activity $\left(\% \mathrm{H}_{2} \mathrm{~S}\right.$ conversion $\left./ \mathrm{m}^{2}\right)$ and the sulfur adsorption of porous materials. See Tables I and II for the numbers: $O$, carbonaceous materials (no. 1-9); $\square$, zeolites (no. 10-15); $\Delta$, other materials (no. 16-27).

Therefore it is apparent that in CaA and chabasite the surface area of the sulfur in the micropores is less than in $\mathrm{NaX}$.

(3) The activity of silica, even the microporous form, is rather low compared to active carbons and zeolites. The same is true for the adsorption of sulfur. The influence of the average pore size on the activity is very pronounced (compare $\mathrm{SiO}_{2}-380$ and $\mathrm{SiO}_{2}-\mathrm{FD} 1$ in Table III). Highly porous silicic acid is disclosed in a patent (Bayer, 1924) as a catalyst for the reaction between $\mathrm{H}_{2} \mathrm{~S}$ and $\mathrm{O}_{2}$. In a more recent patent (Johnson and Kerr, 1961) it is, however, reported that silica gel failed to catalyze the desired reaction. This apparent contradiction is probably due to a difference in the average pore diameter of the samples used.

(4) Also for the alumina catalysts the activity and the amount of sorbed sulfur increase with decreasing pore size. Prettre and Sion (1959) found the same distinct influence of the average pore diameter: a material with $\bar{d}_{\mathrm{p}}=30 \AA$ had a considerably higher activity than a material with $\bar{d}_{p}=200$ $\AA$.

Although the activity of the alumina catalysts is high in the initial period, a continuous decrease of the activity is observed. A constant activity level is not reached even after $40 \mathrm{~h}$ of reaction. Johnson and Kerr (1961) reported a relatively poor yield of sulfur for activated alumina in the initial period; the reaction stopped after $2 \mathrm{~h}$. The decrease of the activity is not caused by the filling of pores with sulfur because the surface area hardly decreases. Landau et al. (1968) showed that the formation of sulfate at the alumina surface causes the continuous decrease. They report that the fouling by sulfate can be reduced if alumina low in iron is used.

II. Influence of the Surface Composition of Materials with $\bar{d}_{\mathrm{p}}>10 \AA$. A first point of discussion will be the differences in the activity between some materials $\left(\mathrm{Al}_{2} \mathrm{O}_{3}, \mathrm{SiO}_{2}\right.$, and $\mathrm{TiO}_{2}$ ) with a comparable pore structure but different chemical composition. Next, the influence of water on activity and surface composition will be discussed. Finally the exceptional behavior of the iron oxide catalyst needs some discussion.

(1) $\mathrm{Al}_{2} \mathrm{O}_{3}, \mathrm{SiO}_{2}$, and $\mathrm{TiO}_{2}$. As Figures 3 and 4 show, there are remarkable differences in activity between the oxidic materials. For instance, the activity of alumina is always higher than that of silica, even when silica with a small average pore diameter is used. The amount of adsorbed sulfur is also somewhat higher in the case of alumina (Table II). This difference in sulfur adsorption behavior is probably connected with the possibility of the presence of Lewis acid sites at the surface of the alumina. Parry (1963) demonstrated that these 
sites are present on alumina but not on silica. The adsorption of sulfur is enhanced by the interaction between the Lewis base sulfur and the Lewis acid centers, i.e., aluminum ions at the surface. Also in the case of $\mathrm{TiO}_{2}$ it is likely that the rather high activity is connected with the presence of Lewis acid sites. Primet et al. (1971) found that removal of isolated $\mathrm{OH}$ groups on $\mathrm{TiO}_{2}$ gave rise to strong Lewis acid sites. Here the activity is rather low, which is connected with the presence of Brönsted or protonic acid sites. This unfavorable influence of Brönsted acid sites on the sorption of sulfur was clearly demonstrated by Landau et al. (1964), who studied the decomposition of, $\mathrm{CS}_{2}$.

It is noteworthy that Lewis bases such as pyridine and water can compete with sulfur for the occupation of Lewis acid sites. Some tentative experiments showed that addition of pyridine to the feed leads to a strong activity decrease in the case of $\mathrm{TiO}_{2}$ and $\mathrm{Al}_{2} \mathrm{O}_{3}$-Degussa. The effect of water is discussed below.

(2) Influence of Admixing Water to the Feed. Admixing of water to the feed leads to a decrease of the activity. As Table III shows, this effect is pronounced for silica and wide-pore alumina. An explanation could be that the high partial pressure of water shifts the equilibrium:

$3 / 8 \mathrm{~S}_{8}+2 \mathrm{H}_{2} \mathrm{O} \rightarrow 2 \mathrm{H}_{2} \mathrm{~S}+\mathrm{SO}_{2}\left(200^{\circ} \mathrm{C}, K_{\mathrm{p}}=2 \times 10^{-6} \mathrm{~atm}^{5 / 8}\right)$

Calculation of the equilibrium constant $\left(K_{\mathrm{p}}\right)$ based on thermodynamic data showed that this reaction does not account for the observed activity decrease. A retarding effect of water in the mechanism of the autocatalytic reaction on the sulfur surface is also improbable, because when using activated carbon only a small decrease is observed.

The only satisfactory explanation is that sorption of water changes the character of the surface of the porous material, which leads to a decrease of the amount of sorbed sulfur. In the case of $\mathrm{Al}_{2} \mathrm{O}_{3}$ and $\mathrm{TiO}_{2}$ water will occupy Lewis acid sites and in this way lower the adsorption of sulfur. In the case of silica the concentration of $\mathrm{OH}$ groups will be raised, and the surface becomes more hydrophilic. Of course this will also lead to a decrease of sulfur active sites.

In the microporous materials such as active carbons and zeolites the strong adsorption of sulfur is especially caused by the small average pore diameter. Water has in this case only a small effect on the rate because the composition of the surface is only a secondary factor in the sulfur adsorption. It is interesting to note that the water effect is less pronounced for a small-pore alumina compared to a wide-pore alumina (Table III). This again points to the better adsorption of sulfur in microporous materials.

The lower selectivity in the presence of water is a consequence of the fact that the contribution of the selective autocatalytic mechanism to the overall rate decreases. The oxidation catalyzed by impurities such as iron oxide gains importance. The reverse occurs in the oxidation of sulfide solutions where the presence of elemental sulfur or polysulfide sulfur $\left(\mathrm{S}_{x} \mathrm{H}\right)$ enhances the selective oxidation (Rosenwald et al., 1975).

(3) The Influence of a Heat Pretreatment at $500^{\circ} \mathrm{C}$ on the Initial Rate. A heat treatment at $500^{\circ} \mathrm{C}$ creates a temporarily more active catalyst because more Lewis acid sites are formed or by other reactions the surface becomes more hydrophobic (Figure 2). The water formed in the oxidation reaction has, however, an opposite effect. This explains the marked difference in the initial period caused by heating of the materials. Puri et al. (1971) degassed active carbons and carbon blacks at $1000^{\circ} \mathrm{C}$ prior to testing their activity for $\mathrm{H}_{2} \mathrm{~S}$ oxidation. A significant higher activity compared to the untreated samples was observed. They demonstrated that oxygen groups $\left(\mathrm{C}_{x} \mathrm{O}_{y}\right)$ at the surface decompose leaving a more hydrophobic surface behind.
(4) the Catalytic Activity of $\mathrm{Fe}_{2} \mathrm{O}_{3}$. Iron oxide shows a catalytic behavior which deviates from the materials already discussed. The combination of high activity and low selectivity is striking. Under our experimental conditions all the available oxygen is consumed and the primary product is $\mathrm{SO}_{2}$. In the reactor outlet both $\mathrm{SO}_{2}$ and $\mathrm{H}_{2} \mathrm{~S}$ are present, although the reaction between these species is thermodynamically favored. The important reactions in this case are:

$$
\begin{gathered}
2 \mathrm{H}_{2} \mathrm{~S}+3 \mathrm{O}_{2} \rightarrow 2 \mathrm{SO}_{2}+2 \mathrm{H}_{2} \mathrm{O} \text { (fast) } \\
\mathrm{SO}_{2}+2 \mathrm{H}_{2} \mathrm{~S} \rightarrow 3 \mathrm{~S}+2 \mathrm{H}_{2} \mathrm{O} \text { (slow) }
\end{gathered}
$$

The iron oxide is partly converted into sulfide, judging the change of color from brown-red to black. The autocatalytic reaction on sulfur does not play a predominant role because the selectivity toward elemental sulfur is too small. An oxidation-reduction mechanism involving the heavy metal ion is very likely. Other investigators (Cook and Ross, 1973; Ross and Jeanes, 1974) used the oxides of cobalt, molybdenum, nickel, and tungsten or their combinations for the direct conversion of $\mathrm{H}_{2} \mathrm{~S}$ into $\mathrm{SO}_{2}$. If the heavy metal oxides are used at temperatures of $20-50^{\circ} \mathrm{C}$ in the so-called dry box process (Gmelin, 1953), where sulfur can deposit on their surface, a high selectivity may be obtained. This is caused either by the high selectivity of iron oxide or sulfide itself or by catalytic effect of the adsorbed sulfur.

III. A Theoretical Approach to the Relation between (a) Pore Diameter and Chemical Composition of the Surface and (b) Sulfur Adsorption and Catalytic Activity. At relative sulfur vapor pressures above 0.25 the condensation of sulfur in cylindrical pores with $d_{\mathrm{p}}>30 \AA$ can be described in terms of the Kelvin equation:

$$
\ln \left(\frac{P}{P_{0}}\right)=-\frac{\gamma V_{\mathrm{m}} \cos \theta}{r R T}
$$

where $P$ is the vapor pressure above the curved surface in a pore with radius $r, \mathrm{P}_{0}$ is the vapor pressure above a planar surface, $\gamma$ is the surface tension of the liquid, $V_{\mathrm{m}}$ is the molar volume of the liquid, $\theta$ is the angle of contact, $R$ is the gas constant, and $T$ is the absolute temperature. This equation clearly demonstrates that both influences of the pore structure parameter $(r)$ and the adsorbate-adsorbent interaction parameter $(\gamma \cos \theta)$ determine the capillary condensation. The higher sulfur adsorption in small pore materials is in agreement with this equation. The activity lowering effect of water in the case of silica is connected with a decrease of the sulfur-adsorbent interaction.

In the case of micropores $\left(d_{p} \approx 10 \AA\right)$ the Kelvin equation does not apply because the pores are commensurate with the adsorbed molecules, which leads to a substantial increase in the adsorption energy as compared to the corresponding values for macro- or meso-porous adsorbents of a similar chemical nature. The rather strong adsorption of hydrophobic sulfur in the ionic zeolite may be somewhat surprising. Dubinin (1975) explains this fact by the existence of a dispersion interaction, i.e., between sodium ions in $\mathrm{NaX}$ and electron clouds of the sulfur molecules.

\section{Conclusions}

I. Porous Structure. Pore diameter is a very important factor in determining the catalytic activity. In case the pores are of the same order of magnitude as the adsorbed sulfur molecules $(5-10 \AA)$ the actual catalyst sulfur is strongly adsorbed. The autocatalytic reaction leads to a high activity per square meter and a high selectivity. Besides micropores the presence of an interconnecting net of meso and macropores is essential to assure the accessibility of the catalyst sulfur which is adsorbed in the micropores.

II. Chemical Composition. The chemical composition of 
the surface is an important factor for the meso- and macroporous materials. Generally the sulfur adsorption and activity are low as in the case of $\mathrm{SiO}_{2}, \mathrm{MgO}$, and carbon blacks. The presence of Lewis acid sites of the surface of $\mathrm{Al}_{2} \mathrm{O}_{3}$ and $\mathrm{TiO}_{2}$ may enhance sulfur adsorption and thereby the activity. These acid sites can be poisoned with Lewis bases such as water or pyridine.

Iron oxide shows exceptional behavior, because it combines a high activity with a very low selectivity. An oxidation-reduction mechanism involving the iron ion is very likely. Other investigators (Cook and Ross, 1973; Ross and Jeanes, 1974) found that the oxides of $\mathrm{Co}, \mathrm{Mo}, \mathrm{Ni}$, and $\mathrm{W}$ also promote the direct conversion of $\mathrm{H}_{2} \mathrm{~S}_{\text {in }} \mathrm{SO}_{2}$.

III. Application in an $\mathrm{H}_{2} \mathrm{~S}$ Removal Process at $200^{\circ} \mathrm{C}$. When the conversion per unit weight of materials is considered at the stationary activity level the following conclusions can be drawn.

Active Charcoals. The industrial active charcoals combine a high activity with a moderate selectivity. The presence of water in the feed does not give a large activity decrease.

Zeolites. The zeolite NaX is the most suitable of all the zeolites in the $\mathrm{H}_{2} \mathrm{~S}$ oxidation process and is competitive with the industrial active charcoals regarding activity and selectivity.

Alumina. The very high activity in the initial period is followed by a continuous activity decrease due to sulfate fouling. Another disadvantage is the poisoning effect of water in the feed.

Iron Oxide. Only for the conversion of $\mathrm{H}_{2} \mathrm{~S}$ into $\mathrm{SO}_{2}$ this material is an excellent catalyst. When used at low temperatures $\left(40^{\circ} \mathrm{C}\right)$ as in the "dry box" process (Gmelin, 1953), it is suitable for selective conversion into sulfur.

$\mathrm{ZrO}_{2}$ and $\mathrm{TiO}_{2}$ can be used for a selective conversion of $\mathrm{H}_{2} \mathrm{~S}$ into sulfur. Per unit of reactor volume $\mathrm{ZrO}_{2}$ is the most active catalyst of all the materials under investigation.

\section{Acknowledgment}

We wish to thank Mr. F. Derks for carrying out part of the experimental work. The investigations were supported by the organization for chemical research in the Netherlands (SON) with financial aid of the Dutch organization for the advancement of pure research (ZWO).

\section{Literature Cited}

Bayer, F., Company, British Patent, 207196 (1924).

Bond, R. L., "Porous Carbon Solids," Academic Press, London, 1967.

Breck, D. W., "Zeolite Molecular Sieves,'" Wiley-Interscience, New York, N.Y., 1974

Cook, W. G. Ross, R A Atmos Environ 7, 145 (1973)

Dubinin, M. M., Prog. Surf. Membr. Sci., 9, $1(1975)$.

Fricke, R., Ackermann, P., Z. Elektrochem., 40, 663 (1934).

"Gmelin's Handbuch der Anorganischen Chemie," 9A, 241 (1953)

Johnson, G. C., Kerr, G. T., U.S. Patent 2971824 (1961).

Krause, A. Plura, I. Monatsh Chem, 96, 1581 (1965)

Landau, M., Molyneux, A., Zadora-Chrzatowski, W., Chem. Ind., 1949 (Nov 21, 1964)

Landau, M., Molyneux, A., Houghton, R., Eng. Gas. Solid Rect. Proc. Symp., 228 (1968)

Okkerse, C., Thesis, T. H. Delft, 1961.

Parry, E. P., J. Catal., 2, 371 (1963).

Prettre, M. Sion, R. Z. Elektrochem 63, t00 (1959).

Primet, M., Pichat, P., Mathieu, M. V., J. Phys. Chem., 75, $1221(1971)$

Puri, B. R., Kumar, B., Kalra, K., Indian J. Chem., 9, 970 (1971).

Rijnten, H. Th., Thesis, T. H. Delft, 1971

Rosenwald, R. H., Hamblin, R. J. J., Urban, P., Zimmerman, R. P., ind. Eng. Chem., Prod. Res. Dev., 14, 218 (1975).

Ross. R. A., Jeanes, M. R. Ind Eng. Chem., Prod. Res, Dev., 13, 102 (1974)

Steijns, M., Mars. P., J. Catal., 35, 11 (1974).

Steijns, M., Mars, P., J. Colloid Interface Sci., 57, 175 (1976).

Steijns, M., Peppelenbos, A., Mars, P., J. Colloid Interface Sci., 57, 181 (1976a).

Steijns, M., Koopman, P., Nieuwenhuijse, B., Mars, P., J. Catal., 42, 96 (1976b).

Steijns, M., Derks, F., Verloop, A., Mars, P., J. Catal., 42, 87 (1976c)

Storp, K., Dechema Monogr., 64, 91 (1970).

Swinarski, A., Siedlewski, J., Actes Congr. Int Catal., 2nd, 1960, 2, 2345 (1961)

Received for review April 12, 1976 Accepted November 5, 1976

\title{
Adsorption of Hexachloroplatinic Acid on $\gamma$-Alumina
}

\author{
Elio Santacesaria \\ Centro Nazionale Propulsione ed Energetica del C.N.R.-Milano, Milano, Italy
}

\author{
Sergio Carrà * and Icilio AdamI \\ Istituto di Chimica Fisica, Elettrochimica e Metallurgia del Politecnico di Milano, Milano, Italy
}

\begin{abstract}
The adsorption of hexachloroplatinic acid on $\gamma$-alumina has been studied both in equilibrium and kinetic conditions, in order to improve the preparation techniques of platinum catalysts. The Langmuir model of adsorption on a single site is suitable for interpreting the experimental data and it allows the calculation of the equilibrium constants and the evaluation of the kinetic parameters of the adsorption. The adsorption of hexachloroplatinic acid is preceded by an acid attack of the alumina with dissolution of aluminum. A kinetic analysis suggests that aluminum ions, originated during the chemical attack, are readsorbed on the support together with the hexachloroplatinic anion. The very low enthalpy change shows that the overall adsorption reaction can be assimilated to an ionic exchange. The experimental data suggest that the chemical attack with aluminum dissolution is probably the fundamental step of the adsorption.
\end{abstract}

The adsorption of hexachloroplatinic acid on alumina is an important step in the preparation of supported platinum catalysts at high dispersion. Many aspects of the adsorption of electrolytes from solution have not yet been studied as can be seen from Adamson (1960) and Fripiat et al. (1971). The information available on the subject is rather limited: see, for example, Maatman et al. (1971), Brunelle et al. (1973), and Sacconi (1949). 